\title{
Dual-source inverter for hybrid PV-FC application
}

\author{
Majid Ghani Varzaneh $^{1} \cdot$ Amirhossein Rajaei ${ }^{1}\left[\right.$ Mohammad Mardaneh $^{1}$
}

Received: 24 August 2019 / Accepted: 14 October 2019/ Published online: 24 October 2019

(c) Springer Nature Switzerland AG 2019

\begin{abstract}
Multi input-multi output Power electronic interface for hybrid energy resources has gathered much of interest. In this paper, a new configuration for cascade connection of two Z-Impedance networks is presented which is able to extract power from two separate low voltage energy sources such as photovoltaic panels and fuel cell stacks. The required load power can be shared between two sources which may have different low values. The power sharing is controlled by adjusting the shoot through duration and time shifting. The proposed converter includes the features of conventional Z-source converter such as voltage boost and shoot through immunity of the inverter. Steady state operation principles, switching methods and the main relations for power flow from two inputs to the output are derived. A prototype of the converter is built and tested for different operation modes. The results are compared with simulations and theoretical analysis which verify well performance of the system.
\end{abstract}

Keywords Partial power processing · Isolated Z-source converters · High step up converters · DC/AC converter · Power sharing

\section{Introduction}

Power generation by green sources such as wind and solar energy are growing day to day because of continuously growing energy demand and destructive the effects of fossil fuels on the future of the planet. Free and abundant solar energy has proven to be a challenging source of energy in the most parts of the world. Because of its nature of intermittency to supply power continually, another supplemental power source such as batteries or fuel cells is required. Individual energy provision from these resources is not cost-effective owing to low reliability due to the dependence of produced energy to different atmospheric conditions and high initial costs [1].

In order to develop the concept of hybrid energy systems and required power electronic interface, many researches are conducted [1-19]. Some of them have introduced on new structure and the others studied switching methods. Some studies have added energy storage devices to the system by using auxiliary circuits for better utilization from renewable energies.

The discussed energy sources generate low level DC output voltage. Therefore, they required to be boosted for use as input of conventional voltage source inverters (VSI). Therefore, one extra boosting stage between the source and the VSI is required. Boost converters can play the role but it causes decreasing total efficiency and increase system weight, size, cost, control and complexity, noise and etc. In last few years, many researches have been devoted to introduce new structures to play this role. Also, such systems cannot provide the required gains in most cases because the output level is practically limited due to converter non-idealities. One of the good solutions is the use of impedance network converters first introduced in 2003 as Z-Source inverter (ZSI) [20]. The main advantages of these structures are as follows:

- Low count switching devices.

Amirhossein Rajaei, a.rajaei@sutech.ac.ir; Majid Ghani Varzaneh, m.ghani@sutech.ac.ir; Mohammad Mardaneh, mardaneh@sutech.ac.ir| ${ }^{1}$ Department of Electrical and Electronic Engineering, Shiraz University of Technology, Fars, Iran. 
- High efficiency.

- Low emission and conduction noise.

- Ability to boost the DC-link voltage.

- Eliminating short circuit condition creating by turning on two switch of one leg of the VSI.

- Continuous input current by some topology.

Based on the operation principles of the basic topology (ZSI), many new topologies are proposed to improve the voltage gain, capacitor voltage, low semiconductors count and etc. [21-33].

Using hybrid systems can be implemented via two separated ZSI which sink energy from separated sources and conduct them to grid or the stand alone load. But it increases system weight, size, cost and decrease efficiency. A type of multi input ZSI is introduced in [19]. In that, several voltage or current sources can share their power into one or several ZSI but the input values must be equal in each of any pair placed in symmetric site. It is a practical constraint.

Multi-input Z-source inverters get a number of sources as input. The sources may be voltage or current sources and have different output levels from power, voltage or current viewpoint. Energy storage devices can be used in these systems when some of the inputs are renewable energy kind. It is clear that these systems have special switching methods for charge and discharge of energy storage devices. These switching methods must consider SOC (state of charge) of batteries. The literatures studied hybrid source systems generally employ the theory of multiport converters [1-19].

Some literatures devoted to introduce new topologies of multi-input inverters [34-39]. Some of these introduced a multi-input inverter which is suitable for single-phase applications [36-39] and the others are suitable for threephase applications [34, 35]. Liu et al. [34] has employed double-stage energy conversion method for producing a three-phase output from two DC inputs. This method is simple for implementation but the total system have more cost, size, weight, loss and etc. Singh et al. [35] has used single-stage energy conversion method. This method is better than double-stage energy conversion method but complexity increase is an issue in this situation. Singh et al. [35] employed a good topology by use of eight extra switches which can result lower efficiency.

In this paper, a dual-input ZSI is proposed which extracts energy from two separate low voltage renewable energy sources such as FCs and PVs and conducts it to an AC output load by employing single-stage energy conversion method. Higher voltage of the dual operation, sharing power between two inputs by controlling the shoot through duty cycles of two Z-Impedance networks, and feasibility of implementation the concept for other impedance network structures are the main advantages of the proposed structure. Two switching methods used for power management are described. For each switching method, the relations governing on amount of power sharing by each source and the value of output voltage are explained.

The paper is organized as follows: in Sect. 2, first the proposed converter is introduced and then two switching methods with all important relations and curves are explained. Section 3 is devoted to present simulation and experimental results. In Sect. 4 total conclusions are expressed.

\section{Steady state operation principles and topology analysis of the proposed converter}

The proposed structure is shown in Fig. 1. Power can flows through both Z-impedance networks and supply the load. The proportion of power generated from any of the sources can be determined by shoot through duty cycles of two Z-source converters $\left(D_{s t 1}\right.$ and $\left.D_{s t 2}\right)$.

The Main advantages of the proposed converter are as follows:

- Ability to control the power sharing between two sources by adjusting the switching mode, the amount and phase shift of the shoot through times.

- High DC-link voltage applied to the inverter, not requiring extreme values of $D_{\text {st }}$.

- Power sharing by two Impedance networks without any extra elements.

- Simple switching methods.

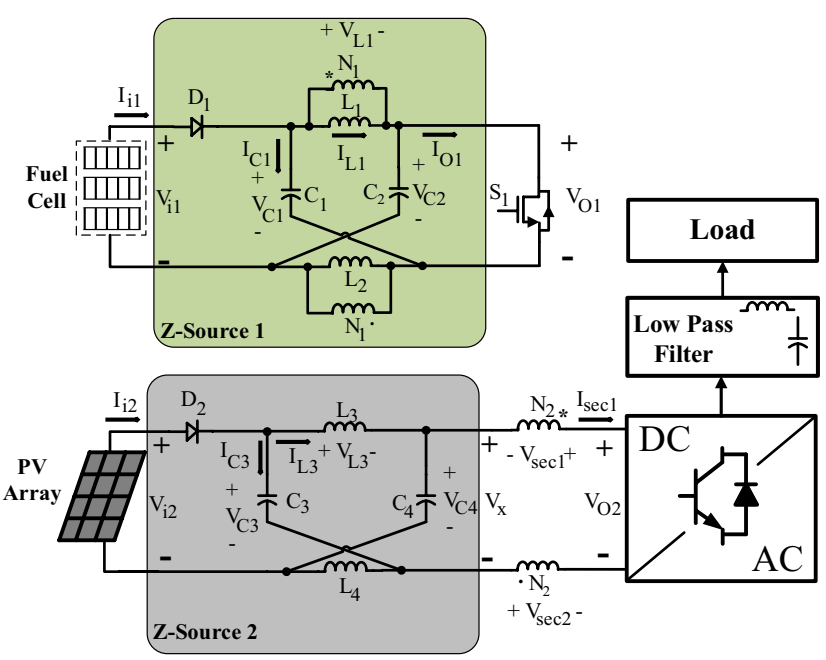

Fig. 1 Schematic diagram of the proposed dual Z-source converter 


\subsection{Circuit description}

As shown in Fig. 1, instead of two inductors, Z-Source 1 contains two transformers in the structure, which the secondary voltages $\left(V_{\text {sec } 1}\right.$ and $\left.V_{\text {sec } 2}\right)$ are in series with $Z$-Source 2, and therefore DC-link voltage of the inverter is equals to $V_{X}+V_{\text {sec } 1}+V_{\text {sec } 2}$. The required inductors of $Z$-Source 1 are the magnetizing inductances of the transformers. Two switching methods which will be explained later, shows expect in optimum switching method. The output are three level signal and it is required that an small $L C$ filter be placed in the output for bypassing the high frequency harmonics.

\subsection{The steady state operation analysis}

Due to the circuit symmetry, circuit analysis is performed for a part of the circuit. Obviously, the other part have the same behavior.

Regarding the structure of the system, Z-Source 1 works similar to the traditional Z-source converter [20] and therefore the relations for the capacitor voltages $\left(V_{C 1}\right.$ and $\left.V_{C 2}\right)$ and the output voltage $\left(V_{O 1}\right)$ are the same:

$\frac{V_{C 1}}{V_{i}}=\frac{1-D_{s t 1}}{1-2 D_{s t 1}}$

$\frac{V_{O 1}}{V_{i 1}}=\frac{1}{1-2 D_{s t 1}}$

where $D_{s t}$ is the duty cycle for shoot through state of $Z$-Source 1 . Considering the voltage drops across $L_{1}$, secondary voltage of the transformer $V_{\text {sec } 1}$ is positive while $S_{1}$ is ON (shoot-through state for Z-Source 1) as $V_{C 1}$ is applied to the primary winding of the transformer (similar for $V_{\text {sec2 }}$ and $V_{C 2}$ ). During this time interval (equals to $\left.D_{s t 1} T\right), V_{s e c 1}$ is:

$V_{\text {sec } 1}=\frac{N_{2}}{N_{1}} V_{C 1}$

During non-shoot through time ( $S_{1}$ is off), the secondary voltage is negative (because of volt-second law for the magnetizing inductors of the transformers) and is equal to:

$V_{\text {sec } 1}=\frac{N_{2}}{N_{1}}\left(V_{i 1}-V_{O 1}\right)$

According to the values of $D_{s t 1}$ and $D_{s t 2}$ and time position relative to each other, two operation modes is defined as shown in Fig. 2. In the following, the operation principles of the converter in both modes are described.

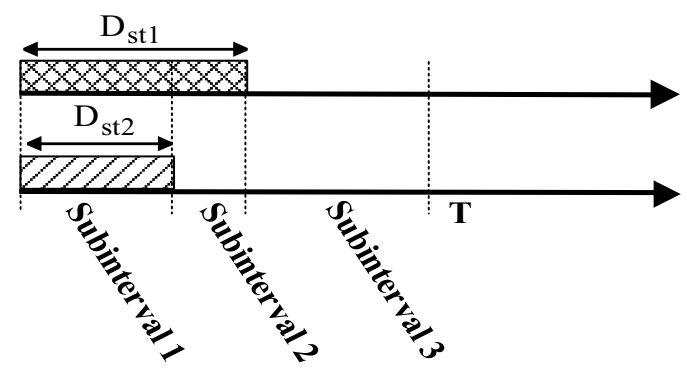

(a)

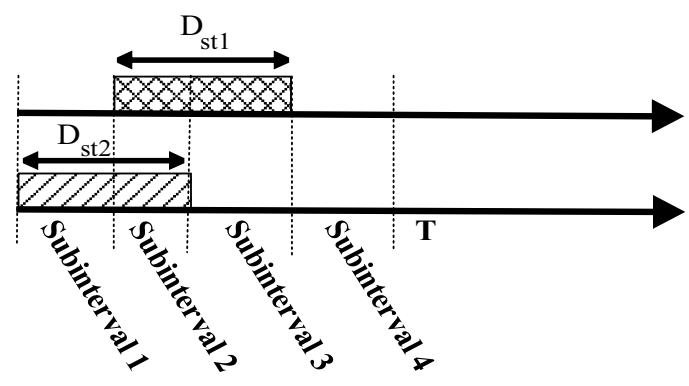

(b)

Fig. 2 Possible shoot through states for $D_{s t 1}$ and $D_{s t 2}$. a Mode I, b Mode II

\subsubsection{Mode I}

In this mode of operation, two Z-Source networks goes to shoot through state, simultaneously. But shoot through times may differ (Fig. 2a). During $\left(D_{s t 1}-D_{s t 2}\right) T$ (which is subinterval 2), diode $D_{2}$ may be conducting or not, which depends on the inputs voltage level, the output current level and the duty cycles values $\left(D_{s t 1}\right.$ and $\left.D_{\text {st } 2}\right)$. In the next, it is supposed that all symmetric elements have same values and behavior (such as transformers turn ratio (n) or $L_{3}$ and $L_{4}$ or ...). Figure 3 Shows the equivalent circuits for all three states of the converter in Mode I and actual current directions (red dashed lines) in all the circuit branches.

According to Fig. 3a, in $D_{\text {st2 }} T$ (subinterval 1), because both Z-sources are in shoot through state, so $V_{L 3}=V_{C 3}+2 V_{\text {sec } 1}=V_{C 3}+2 n V_{C 1}, V_{O 2}^{1}=0$. It is clear that $L_{3}$ charges with the value is larger than $V_{C 1}$ (in compared to classic Z-source) and so when Z-source 2 inters in nonshoot through state it produces the value larger than the inductor voltage in classic Z-source.

When the converter is in subinterval $2\left(\left(D_{s t 1}-D_{s t 2}\right) T\right)$, $V_{O 2}^{2}=V_{i 2}-2 V_{L 3}+2 V_{s e c 1}=V_{i 2}-2 V_{L 3}+2 n V_{C 1} \quad$ a n d when the converter is in subinterval $3\left(\left(1-D_{s t 1}\right) T\right)$, $V_{O 2}^{3}=V_{i 2}-2 V_{L 3}+2 V_{\text {sec } 1}=V_{i 2}-2 V_{L 3}+2\left(V_{i 1}-V_{C 1}\right)$. 
Fig. 3 The equivalent circuits of the converter in Mode $I$ for a $D_{s t 2} T$. (subinterval 1) b $\left(D_{s t 1}-D_{s t 2}\right) T$ (subinterval 2) c $\left(1-D_{s t 1}\right) T$ (subinterval 3)

Because $V_{i 1}-V_{C 1}<V_{C 1}$ so $V_{O 2}^{2}>V_{O 2}^{3}$. In other words, $V_{O 2}$ is a three level signal which is zero when $Z$-source 2 is in shoot through state (subinterval 1) and have non-zero values in other states (subinterval 2 and 3). Figure 4 illustrates $V_{\mathrm{O}_{2}}$ with the related shoot through duty cycles for the converter. In order to eliminate flowing the high order sinusoidal voltage harmonics, an LC filter is required in the output of the inverter.

In the following, the values of the important variables in this Mode will be calculated. Employing volt-second law for inductor $\angle 3$ yields:

$$
\begin{aligned}
& \left(2 n V_{C 1}+V_{C 3}\right) D_{s t 2}+\left(V_{i 2}-V_{C 3}\right)\left(D_{s t 1}-D_{s t 2}\right) T \\
& \quad+\left(V_{i 2}-V_{C 3}\right)\left(1-D_{s t 1}\right) T=0
\end{aligned}
$$

Simplifying (5) and implying $k v /$ for the circuits result:

$$
\begin{aligned}
& V_{C 3}=V_{i 1}+\frac{\left(1-D_{s t 2}\right) \cdot\left(1-2 D_{s t 1}\right) V_{i 2}}{2 n D_{s t 2}\left(1-D_{s t 1}\right)} \\
& V_{O 2}^{2}=V_{i 1}+\left(\frac{D_{s t 2}\left(1-2 D_{s t 1}\right)}{2 n\left(1-D_{s t 1}\right)\left(1-2 D_{s t 2}\right)}\right) V_{i 2} \\
& V_{O 2}^{3}=V_{i 1}+\left(\frac{D_{s t 2}\left(1-2 D_{s t 1}\right)}{2 n\left(D_{s t 1} D_{s t 2}-D_{s t 1}+D_{s t 2}\right)}\right) V_{i 2}
\end{aligned}
$$

where $V_{\mathrm{O} 2}^{2}$ and $V_{\mathrm{O} 2}^{3}$ are the DC-link voltage during subintervals 2 and 3 , respectively.

In order to analyze the power sharing between two networks, the current relations of the system have to be derived in the following. Considering that in the steady state operation, the average currents of the capacitors are zero, the average values of the currents can be calculated as follows:

$I_{L 3}=I_{\text {sec } 1}$

$I_{i 1}=I_{L 1}+n I_{\text {sec } 1}=I_{L 1}+n I_{L 3}$

$I_{i 2}=I_{L 3}$

$I_{O 1}=n I_{\text {sec } 1}+I_{L 1}=n I_{L 3}+I_{L 1}$

According to the circuit operation in this Mode; $I_{\text {sec } 1}$ can be expressed as follow:

$I_{s e c 1}=2 I_{L 3} \cdot D_{s t 2}+I_{I n v}^{2} \cdot\left(D_{s t 1}-D_{s t 2}\right)+I_{I n v}^{3} \cdot\left(1-D_{s t 1}\right)$
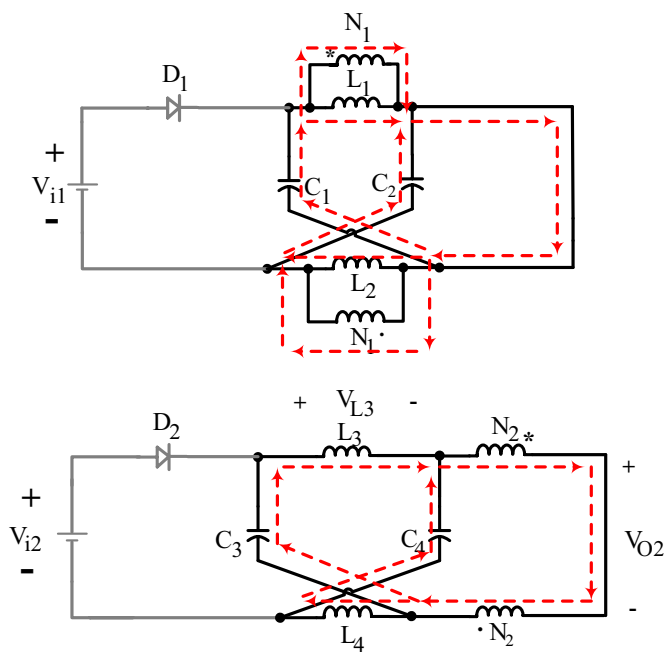

(a)
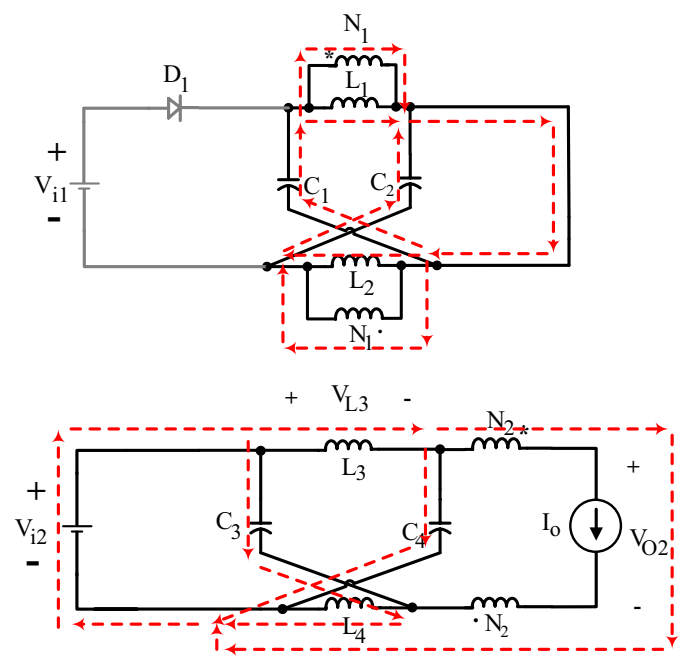

(b)
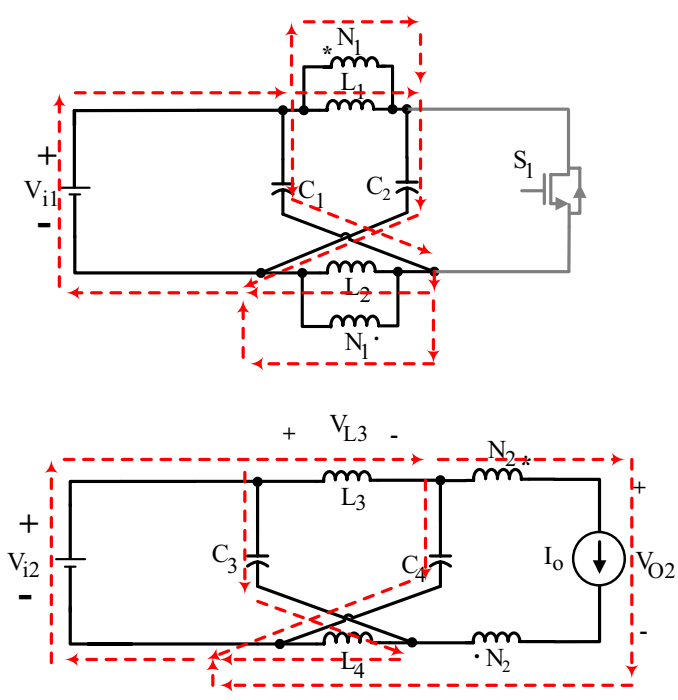

(c) 


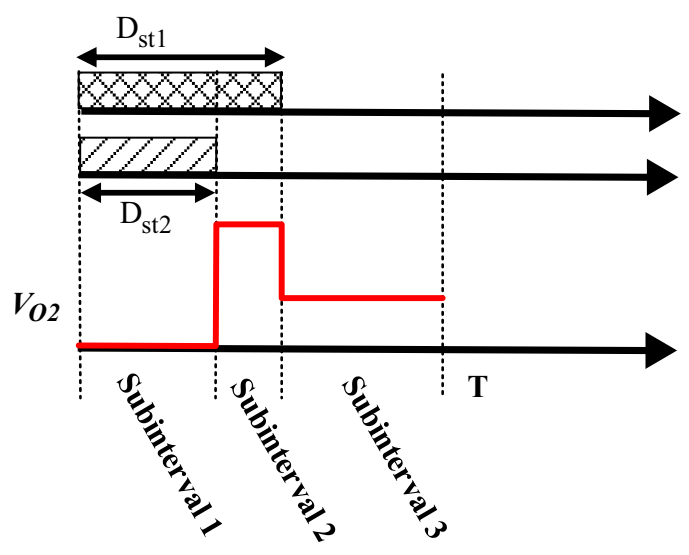

Fig. 4 The schematic waveform of $V_{\mathrm{O} 2}$ for Mode I

where $l_{I n v}^{2}$ and $l_{l n v}^{3}$ are the average input values of the inverter current during subinterval 2 and 3, respectively. Employing (9) and (13) yields:

$I_{L 3}=I_{l n v}^{2}+I_{l n v}^{3} \cdot\left(\frac{1-D_{s t 1}}{D_{s t 1}-D_{s t 2}}\right)$

Again for $I_{O 1}$

$$
\begin{aligned}
I_{O 1}= & 2 l_{L 1} \cdot D_{s t 1}+2 n l_{s e c 1}^{1} \cdot D_{s t 2} \\
& +2 n l_{s e c 1}^{2} \cdot\left(D_{s t 1}-D_{s t 2}\right)
\end{aligned}
$$

In (15), $l_{\text {sec } 1}^{1}$ and $l_{\text {sec } 1}^{2}$ imply to the average current values of the transformers secondary windings in the subintervals 1 and 2 , respectively. They are equal to $2 I_{L 3}$ and $I_{I n V^{\prime}}^{2}$ respectively. So (15) can be rewrote as follow:

$$
\begin{aligned}
I_{O 1}= & 2 I_{L 1} \cdot D_{s t 1}+4 n I_{L 3} \cdot D_{s t 2} \\
& +2 n I_{l n v}^{2} \cdot\left(D_{s t 1}-D_{s t 2}\right)
\end{aligned}
$$

Considering (12), (14) and (16) shows:

$$
I_{L 1}=I_{I n v}^{2}+I_{I n v}^{3} \cdot\left(\frac{\left(4 D_{s t 2}-1\right) \cdot\left(1-D_{s t 1}\right)}{D_{s t 1}-D_{s t 2}}\right)
$$

Replacing (13) and (17) in (10) results:

$$
I_{i 1}=I_{I n v}^{2}+I_{I n v}^{3} \cdot\left(\frac{\left(1-D_{s t 1}\right)\left(2 D_{s t 2}-D_{s t 1}\right)}{\left(D_{s t 1}-D_{s t 2}\right)\left(1-D_{s t 1}-D_{s t 2}\right)}\right)
$$

Replacing (14) in (11) results:

$$
I_{i 2}=I_{\text {Inv }}^{2}+I_{\text {Inv }}^{3} \cdot \frac{1-D_{s t 1}}{D_{s t 1}-D_{s t 2}}
$$

The values of active power produced by each sources can be calculated by multiplying the value of any source voltage

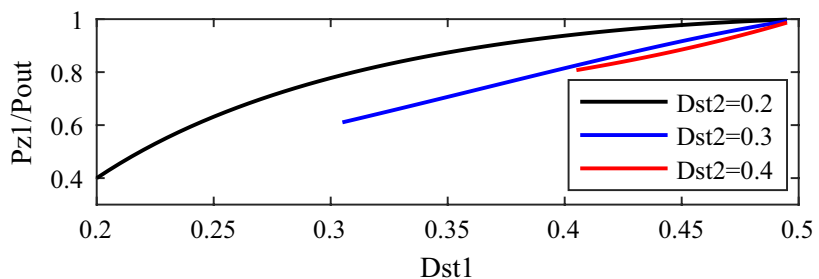

Fig. 5 The ratio of $P_{z 1}$ to $P_{\text {out }}$ in Mode $I$ for $V_{i 1}=V_{i 2}, n=1$

value to the average value of its current by using (18) and (19). Therefore, active power of source $1\left(P_{z 1}\right)$ and source 2 $\left(P_{z 2}\right)$ are calculated as follow:

$P_{z 1}=V_{i 1} \cdot\left(\begin{array}{c}I_{l n v}^{2} \\ +l_{l n v}^{3} \cdot\left(\frac{\left(1-D_{s t 1}\right)\left(2 D_{s t 2}-D_{s t 1}\right)}{\left(D_{s t 1}-D_{s t 2}\right)\left(1-D_{s t 1}-D_{s t 2}\right)}\right)\end{array}\right)$

$P_{z 2}=V_{i 2} \cdot\left(l_{l n v}^{2}+l_{l n v}^{3} \cdot \frac{1-D_{s t 1}}{D_{s t 1}-D_{s t 2}}\right)$

Obviously, the total output power is $P_{z 1}+P_{z 2}$, so:

$P_{\text {out }}=P_{z 1}+P_{z 2}$

When the proposed topology operates in Mode I, via controlling $D_{s t 1}$ and $D_{s t 2}, V_{O 2}$ and the values of the active power flowed to the load can be controlled. Now, for evaluation the operation of the converter from power sharing viewpoint, the curve showing $\frac{P_{z 1}}{P_{\text {out }}}$ for $V_{i 1}=V_{i 2}$ for different values of $D_{s t 1}$ and $D_{s t 2}$ is drawn.

Figure 5 shows an increase in $D_{s t 1}$ or a decrease in $D_{s t 2}$ causes increasing The ratio of $P_{z 1}$ to $P_{\text {out }}$. Generally, when the system operates, the main variable which have to be controlled are the values of $V_{O 2}$ and $P_{z 1}$. This control algorithm is performed by controller. So the controller has to be solved the (7), (8) and (20) to find out the sufficient values of $D_{s t 1}$ and $D_{s t 2}$. That; (7) and (8) have to be calculated for achieving $V_{\mathrm{O} 2}$ is performed by taking average from $V_{\mathrm{O} 2}$. In other words, after filtering, the output applied to the load, is the average value of $V_{O_{2}}$ and so the controller has to calculate the required average value of $V_{\mathrm{O} 2}$ by solving (7) and (8), simultaneously. Also, it can be said when $P_{z 1}$ is chose, $P_{z 2}$ can be calculated from $P_{z 2}=P_{\text {out }}-P_{z 1}$.

If in the converter $D_{s t 1}=D_{s t 2}$, subinterval 2 will be eliminated, the output value will be a two level signal as in classic Z-source inverter and the non-zero level of it is calculated by (8) for $D_{s t 1}=D_{s t 2}$. This is named Optimum Switching Method which is very useful because in the output, the $L C$ filter isn't required. In Fig. 5 , this mode is achieved for $D_{s t 1}=D_{s t 2}$ and it is seen that controller can simply control the $P_{z 1}$ only by one duty cycle value.

One of the advantages of the proposed structure is having high voltage gain. It means that if the curve of 
$V_{\mathrm{O} 2}$ shown in Fig. 4 is compared with the output value of the classic Z-source inverter in [20], it is deduced that the proposed converter has higher gain in an special operation area. For being clear and better comparison, it is supposed that in this Mode, both input sources are in series and is applied to classic Z-source inverter. The output value which is yielded is compared to the output of proposed converter when $D_{s t 1}=D_{s t 2}=D_{s t}$. In this situation, in the proposed converter, the subinterval 1 doesn't exist and only $V_{o 2}^{3}$ (which is named $V_{O}$ ) exists. By simplification (8), it is resulted:

$V_{O}=\underbrace{\left(\frac{2 n D_{s t}}{\left(1-2 D_{s t}\right)^{2}}\right)}_{K_{1}} V_{i 1}+\underbrace{\frac{1}{1-2 D_{s t}}}_{K_{2}} V_{i 2}$

The output relation for the classic Z-source inverter which its input is $V_{i 1}+V_{i 2}$ is as follow:

$$
\begin{aligned}
V_{O} & =\frac{1}{1-2 D_{s t}}\left(V_{i 1}+V_{i 2}\right) \\
& =\underbrace{\frac{1}{1-2 D_{s t}}}_{K_{1}^{\prime}} V_{i 1}+\underbrace{\frac{1}{1-2 D_{s t}}}_{K_{2}^{\prime}} V_{i 2}
\end{aligned}
$$

For comparison of the values of $V_{O}$ in two converters according to (23) and (24), it can be said because the coefficients $K_{2}$ and $K_{2}^{\prime}$ are the same, so the coefficients $K_{1}$ and $K_{1}^{\prime}$ should be compared. It is possible $n=1$ and the coefficients are drawn for $0<D_{o v}<0.5$. Figure 6 shows both curves in a plane with logarithmic vertical axis and linear horizontal axis. According to the figure if $0.25<D_{\text {st }}$, it can be said that $K_{1}^{\prime}<K_{1}$ and so the proposed converter has the higher voltage gain than the classic Z-source inverter. In addition, if $n>1, K_{1}$ will be more than when $n=1$ and so it is possible to achieve higher gain with choosing higher $n$.

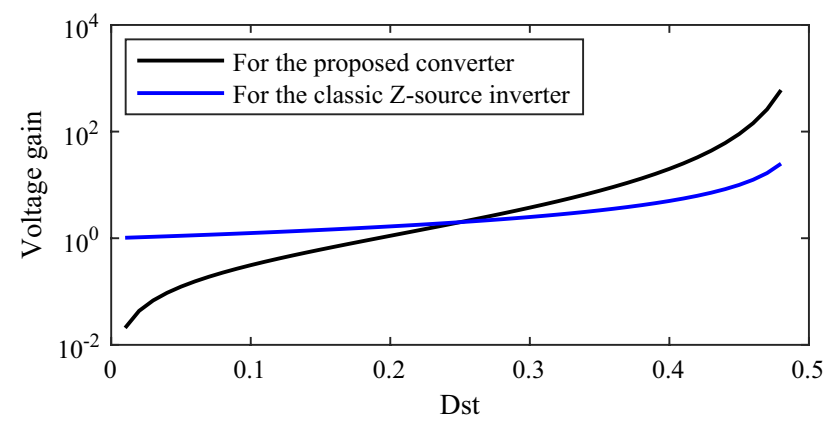

Fig. 6 Comparision of voltage gain $K_{1}$ and $K_{1}^{\prime}$ for $n=1$

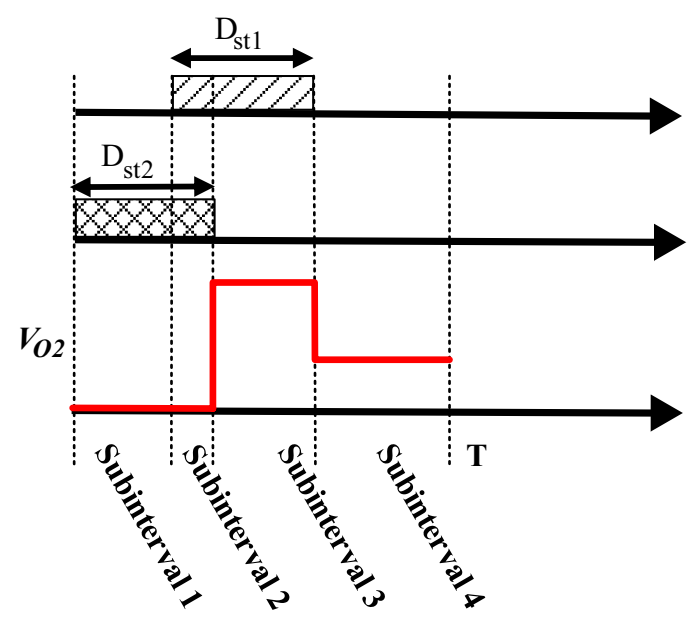

Fig. 7 DC-link voltage waveform for Mode II

\subsubsection{Mode II}

In this Mode, both Z-source networks start shoot through state and finish it in different time. The most advantage of this switching method rather than Mode I is ability to control the contribution of $Z$-source 1 to handle the load. If the system wants to supply the load so that the $Z$-source 2 should have the more contribution, Mode II will be better than Mode I. As Mode I, in one period, when Z-source 1 is in shoot through state and $Z$-source 2 isn't in shoot through state, $V_{O 2}$ has its maximum value. Also, $V_{\mathrm{O}_{2}}$ is a three-level signal. Figure 7 shows shoot through signals and DC-link voltage for this Mode.

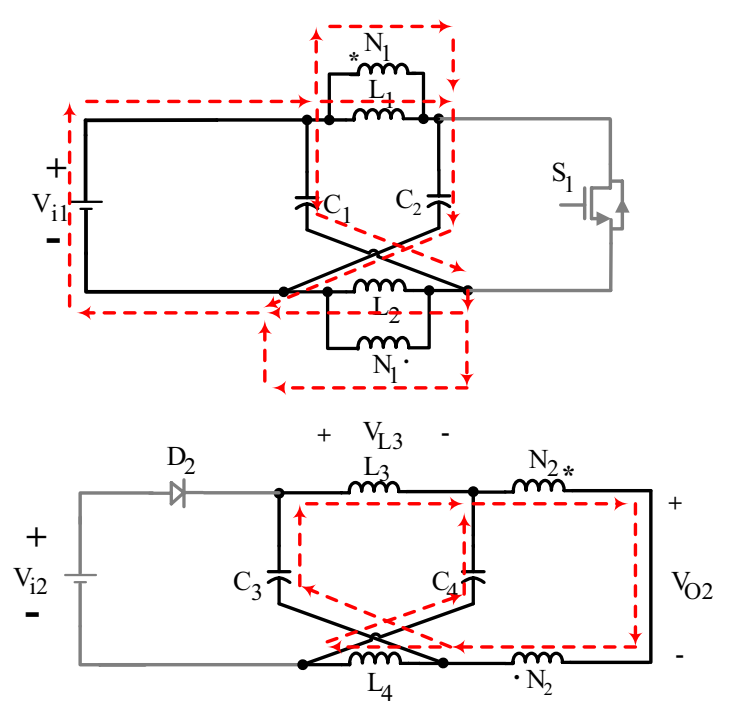

Fig. 8 The equivalent circuit of the converter in Mode II for subinterval 1 
In this Mode, equivalent circuits and current directions is similar to Mode I so that subintervals 2, 3 and 4 in this Mode is equal to subintervals 1, 2 and 3 in Mode $I$, respectively. Only subinterval 1 is different from them and is according to Fig. 8:

If the duty cycle of subinterval 2 is defined as $D_{\text {ov' }}$ Similar to the Mode l, it can be said:

$$
\begin{aligned}
& V_{C 3}=V_{i 1}-\left(\frac{\left(1-D_{s t 2}\right)\left(1-2 D_{s t 1}\right)}{2 n D_{o v}\left(2 D_{s t 2}+D_{s t 1}-2 D_{o v}-1\right)}\right) V_{i 2} \\
& V_{O 2}^{3}=V_{i 1}-\left(\frac{\left(1-2 D_{s t 1}+D_{s t 2}\right)\left(1-2 D_{s t 1}\right)}{n\left(4 D_{s t 2}+2 D_{s t 1}-4 D_{o v}-1\right)}\right) V_{i 2}
\end{aligned}
$$$$
V_{O 2}^{4}=V_{i 1}-\left(\frac{1-2 D_{s t 1}}{2 n\left(D_{s t 1}-2 D_{o v}\right)}\right) V_{i 2}
$$

where $V_{O 2}^{3}$ and $V_{O 2}^{4}$ are the DC-link voltage in subinterval 3 and 4, respectively. Similar to Mode I, it is necessary to extract the active power values produced by Z-source 1 and 2, simultaneously. The calculation and simplification of the relations governing on the system in this Mode is deduced:

$P_{z 1}=V_{i 1} \cdot\left(I_{\text {Inv }}^{3}+I_{\text {Inv }}^{4} \cdot\left(\frac{2\left(2 D_{o v}-D_{s t 1}\right)\left(1-D_{s t 1}-D_{s t 2}+D_{o v}\right)}{\left(D_{s t 1}-D_{o v}\right)\left(1-D_{s t 1}-2 D_{s t 2}+2 D_{o v}\right)}\right)\right)$

$P_{z 2}=V_{i 2} \cdot\left(l_{l n v}^{3}+l_{l n v}^{4} \cdot \frac{1-D_{s t 1}-D_{s t 2}-D_{o v}}{D_{s t 1}-D_{o v}}\right)$

where $I_{I n v}^{3}$ and $I_{I n v}^{4}$ are the average output currents in subinterval 3 and 4 , respectively. As previous section, trying to study the ratio of $P_{z 1}$ to $P_{\text {out }}$. The ratio has been drawn in Fig. 9. In this figure, it is supposed that $D_{s t 1}=D_{s t 2}=D_{s t}$, $V_{i 1}=V_{i 2}$ and the curves are drawn for various $D_{s t}$ and $D_{o v}$.

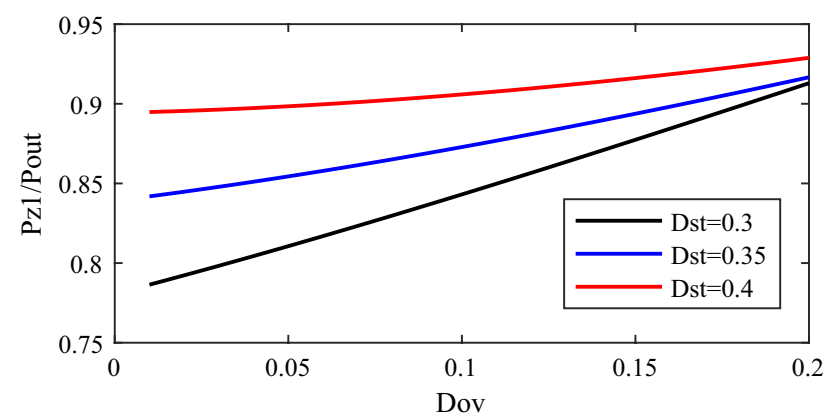

Fig. 9 The ratio of $P_{z 1}$ to $P_{\text {out }}$ in Mode II for $V_{i 1}=V_{i 2}, n=1$, $D_{s t 1}=D_{s t 2}=D_{s t}$

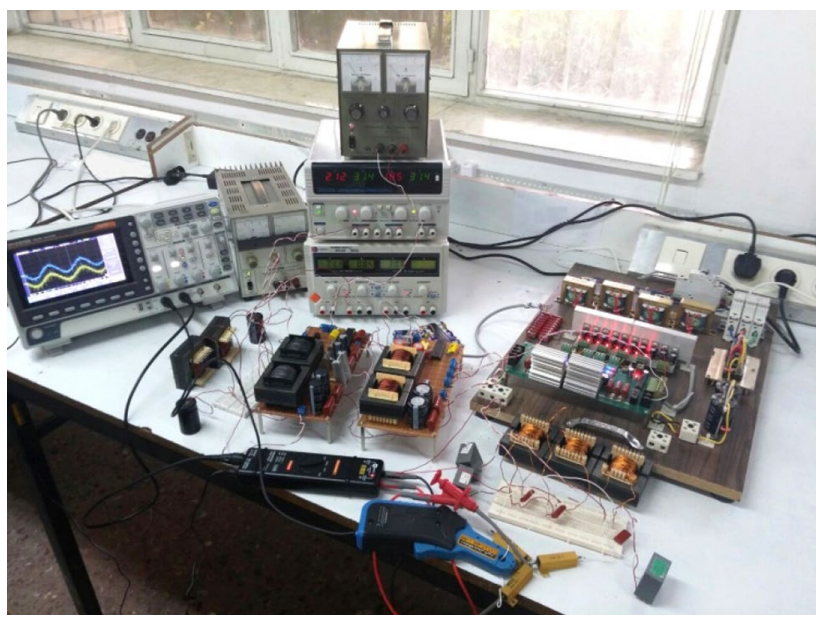

Fig. 10 The experimental setup

Figure 9 shows an increase in the values of $D_{s t}$ or $D_{o v}$, increases $\frac{P_{z 1}}{P_{\text {out }}}$. So with controlling the values of $D_{s t}, D_{o v}$ the contribition of Z-source 1 to handle the load and so sharing the power will be controlled.

\section{Simulation and experimental results}

In order to validate the theoretical analysis, the proposed converter is simulated. Also, a prototype of the converter is built and illustrated in Fig. 10. The results are also shown in this section. The parameters used for simulation and practical experiments are described in Table 1.

First, the converter is simulated and implemented in Mode I. The duty cycles in the subintervals are $D_{\text {st } 1}=0.3, D_{\text {st2 }}=0.2$. The results of simulation are as follow.

Experimental results in this Mode with mentioned values are shown in the following. Comparison of Fig. 11a and Fig. 12a shows the prototype woks very good. Voltage spike which has been appeared in transient time is owing to the leakage inductances of the transformers. As it was expected, DC-link voltage is a three-level signal. Inverter can transfer the current to the load in any time which is necessary. The signal has zero value for the shoot through time of the inverter which is equal to $D_{\text {st } 2} T=0.2 / 20,000$, has the maximum value (as shown in Fig. 4) for $\left(D_{\mathrm{st} 1}-D_{\mathrm{st} 2}\right) T=0.1 / 20,000$ and finally has the value which is lower than the maximum value in previous subinterval for $\left(1-D_{\text {st } 1}\right) T=0.7 / 20,000$. The values can be calculated from (7) and (8) in the ideal converter but the calculated values are approximated because of non-ideal components such as the transformers and the semiconductor devices and etc. 

converter prototype
Table 1 Main parameters of

\begin{tabular}{lll}
\hline Symbols & Definitions & Values \\
\hline$V_{i 1}$ & Z-source 1 input voltage & $20 \mathrm{~V}$ \\
$V_{i 2}$ & Z-source 2 input voltage & $24 \mathrm{~V}$ \\
$R_{\text {load }}$ & The resistance of load (delta connection) & $33 \Omega$ \\
$V_{f}$ & The forward voltage of input diodes & $0.38 \mathrm{~V}$ \\
$V_{\text {on }}$ & The on state voltage of IGBTs & $1.5 \mathrm{~V}$ \\
$n$ & The transformers turn ratio & 1 \\
$r_{p}$ & The transformers primary winding resistance & $0.1 \Omega$ \\
$r_{s}$ & The transformers secondary winding resistance & $0.1 \Omega$ \\
$I_{p}$ & The transformers primary winding leakage inductance & $1.5 \mu \mathrm{H}$ \\
$I_{s}$ & The transformers secondary winding leakage inductance & $1.5 \mu \mathrm{H}$ \\
$L_{1}$ and $L_{2}$ & The transformers magnetizing inductance & $272 \mu \mathrm{H}$ \\
$L_{3}$ and $L_{4}$ & The inductances of Z-source 2 & $380 \mu \mathrm{H}$ \\
$C_{1}, C_{2}, C_{3}$ and $C_{4}$ & Four capacitors of the converter & $1000 \mu \mathrm{F}$ \\
$f$ & Switching frequency & $20 \mathrm{kHz}$ \\
\hline
\end{tabular}

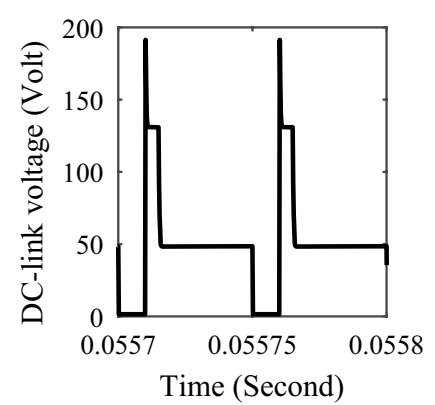

(a)

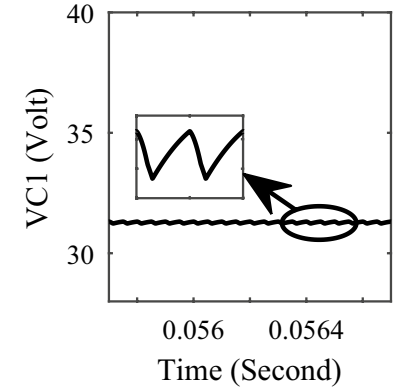

(b)

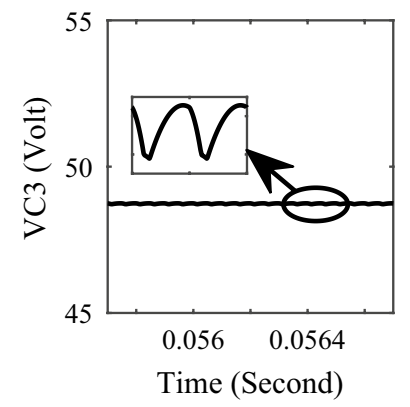

(c)
Fig. 11 The simulated voltage curves for Mode I. a DC-link voltage, b $\mathrm{V}_{\mathrm{C} 1}, \mathbf{c} \mathrm{V}_{\mathrm{C} 3}$

The difference between the primary and secondary current shown in Fig. $13 a$ and $b$ is related to the converter topology. As previous mentioned, the magnetizing inductances of the transformers are used as inductors of $Z$-source 1 . So the primary current is sum of magnetizing current (which is almost high value) and the secondary current referred to the primary side. Therefore, the curves of Fig. 13a and $b$ aren't the same from the value and the shape viewpoint. As seen in Fig. 14a and b, it is clear that

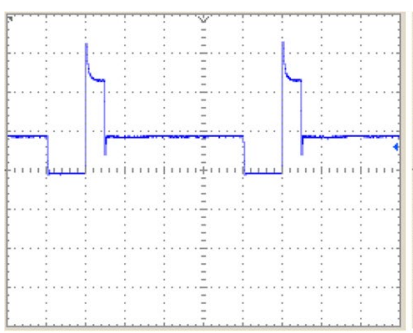

(a)

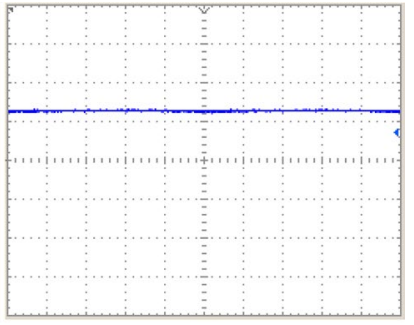

(b)

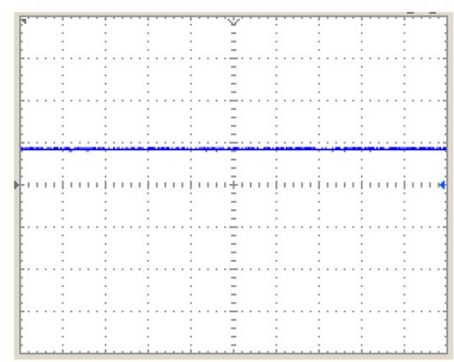

(c)

Fig. 12 Experimental results for Mode I, a DC-link voltage (Volt/ Div $=50$, Time/Div $=10 \mu \mathrm{s}), \mathbf{b ~ V}_{\mathrm{C} 1}($ Volt/Div $=20) \mathbf{c V}_{\mathrm{C} 3}($ Volt/Div $=50)$

simulations and experimental results for the transformers windings current verify each other.

According to Fig. $14 c$ and $d$, when the system is in subinterval 2 , it is clear that the power is shared between two Z-source networks because the current value of input source 2 has been lower than the current in subinterval 3.

Now, it is tried to simulate and implement the system in Mode I/ with $D_{s t 1}=D_{s t 2}=0.2$ and $D_{o v}=0.1$. Other parameters are as previous. The results are as follow (Figs. 15 and 16).

Experimental results in this Mode with the mentioned values are shown in the following (Figs. 17 and 18). 


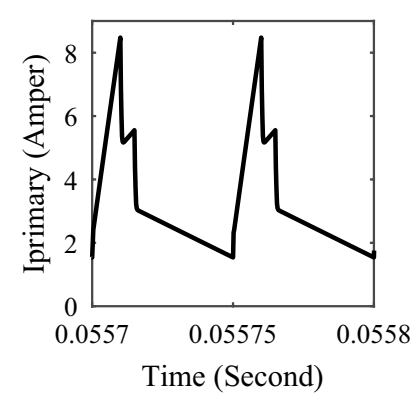

(a)

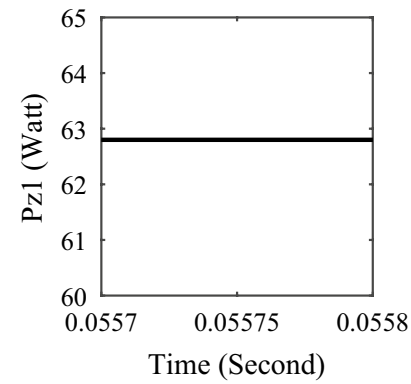

(c)

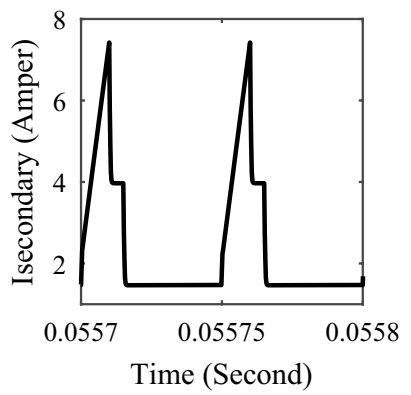

(b)

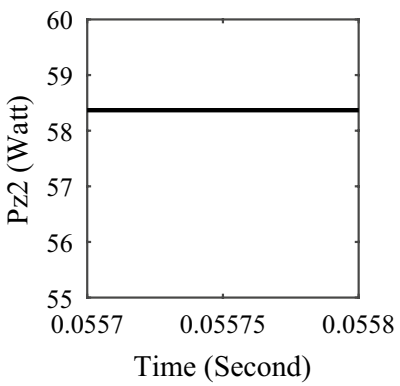

(d)
Fig. 13 The simulated current and power curves for Mode I: a The primary current, b secodary current $\mathbf{c} \mathrm{P}_{\mathrm{z} 1} \mathbf{d} \mathrm{P}_{\mathrm{z} 2}$

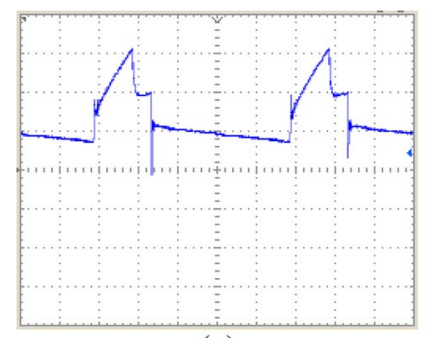

(a)

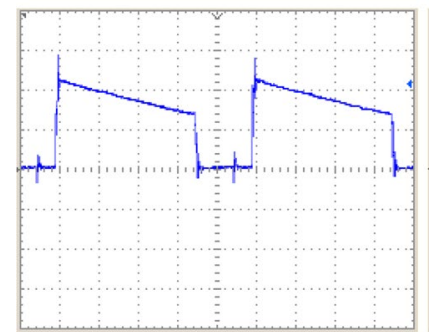

(c)

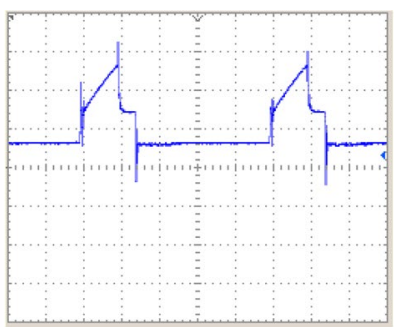

(b)

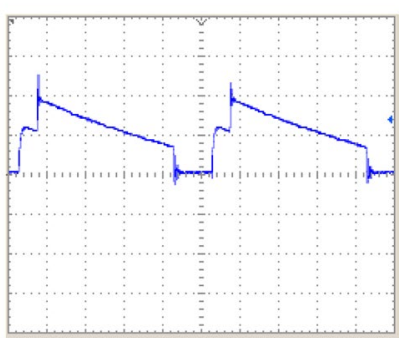

(d)
Fig. 14 Experimental results for Mode I, a primary current, b secondary current, $\mathbf{c} l_{i 1} \mathbf{d} l_{i 2}$. (Amper/Div $=2.7$, Time/Div $=10 \mu \mathrm{s}$ )

\section{Conclusion}

This paper introduced a new topology of two Z-source inverter, which can share the power between two sources with low voltages. The converter can be used

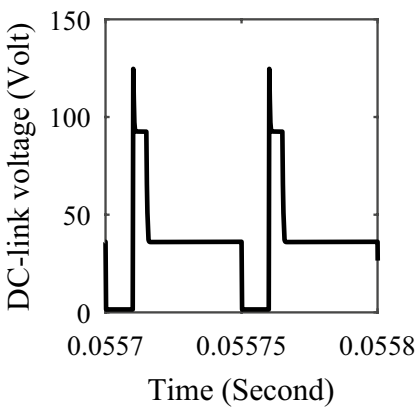

(a)

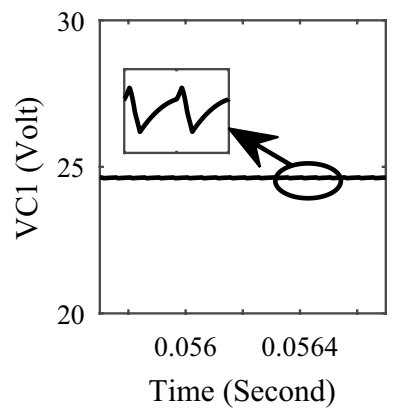

(b)

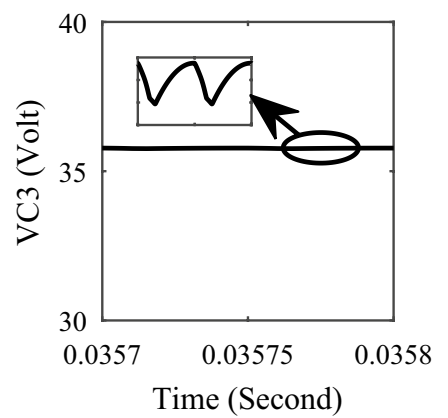

(c)

Fig. 15 The simulated voltage curves for mode II. a DC-link voltage, b $\mathrm{V}_{\mathrm{C} 1}, \mathbf{c} \mathrm{V}_{\mathrm{C} 3}$

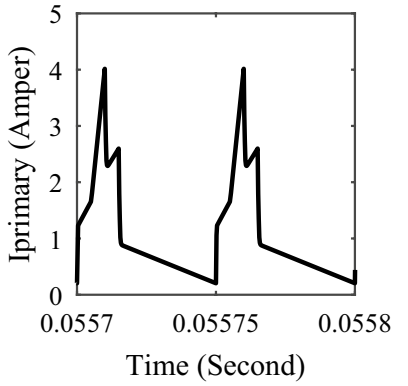

(a)

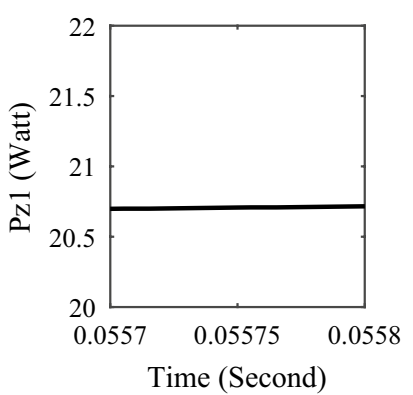

(c)

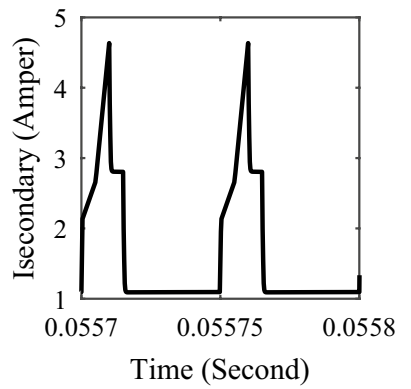

(b)

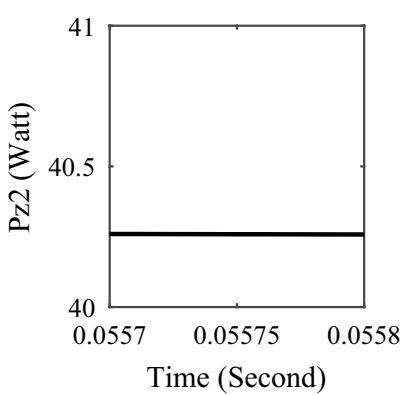

(d)
Fig. 16 The simulated current and power curves for mode II: a The primary current, b secondary current $\mathbf{c} \mathrm{P}_{\mathrm{z} 1} \mathbf{d} \mathrm{P}_{\mathrm{z} 2}$ 


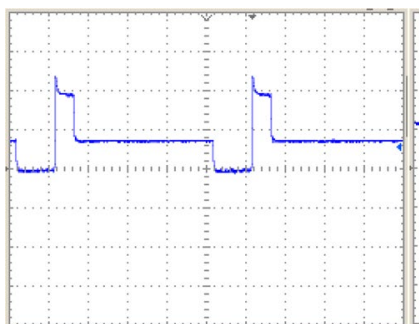

(a)

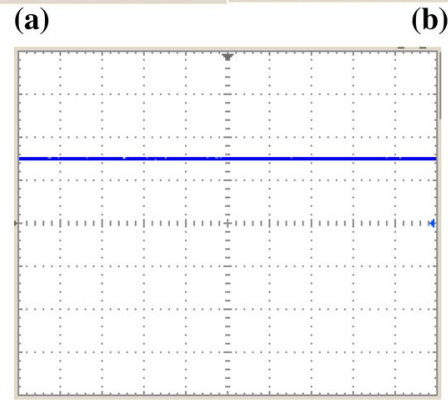

(c)

Fig. 17 Experimental results for Mode II, a DC-link voltage (Volt/ Div $=50$, Time $/$ Div $=10 \mu / s), \mathbf{b}_{C 1}($ Volt/Div $=20) c V_{C 3}($ Volt $/$ Div $=50)$

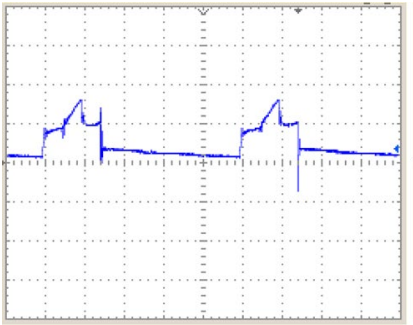

(a)

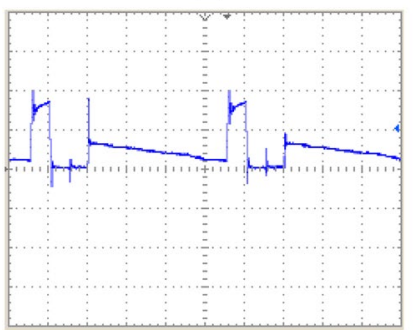

(c)

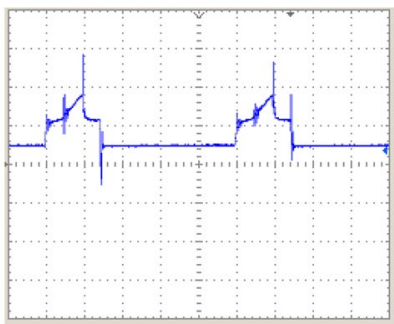

(b)

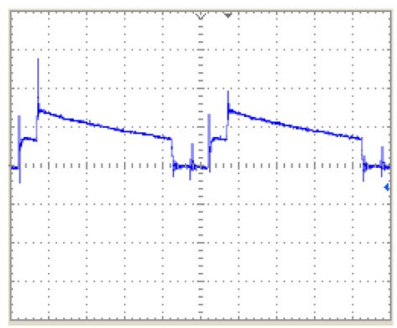

(d)
Fig. 18 Experimental results for Mode II, a primary current, b secondary current, $\mathbf{c} I_{i 1} \mathbf{d} I_{i 2}$. (Amper/Div $=2.7$, Time/Div $=10 \mu \mathrm{s}$ )

in hybrid renewable energy resources. The topology have further advantages such as high voltage gain. Two switching methods with their relation and operation analysis were explained, which showed that by adjusting the shoot through values for two Z-impedance networks, power flow can be controlled. DC-link voltage and the value of shared power can be controlled via choosing switching methods and its duty cycles in each subintervals. The simulation and experimental tests proved the theoretical analysis.

\section{Compliance with ethical standards}

Conflict of interest The authors declare that they have no conflict interest.

Research involving human participants and/or animals Not applicable.

Informed consent All authors confirm the content.

\section{References}

1. Haghighian SK, Hosseini SH (2015) A novel multi-input DC/DC converter with a general power management strategy for grid connected hybrid PV/FC/battery system. In: Power electronics, drives systems and technologies conference (PEDSTC), 2015 6th, 2015. IEEE, pp 1-6

2. Abbassi $R$, Hammami $M$, Chebbi $S$ (2013) Improvement of the integration of a grid-connected wind-photovoltaic hybrid system. In: 2013 International conference on electrical engineering and software applications (ICEESA). IEEE, pp 1-5

3. Ahmadi R, Ferdowsi M (2012) Double-input converters based on $\mathrm{H}$-bridge cells: derivation, small-signal modeling, and power sharing analysis. IEEE Trans Circuits Syst I Regul Pap 59(4):875-888

4. Ahmadi R, Yousefpoor N, Ferdowsi M (2011) Power sharing analysis of double-input converters based on H-bridge cells. In: Electric ship technologies symposium (ESTS). IEEE, pp 111-114

5. Ahmed NA (2012) On-grid hybrid wind/photovoltaic/fuel cell energy system. In: IPEC, 2012 conference on power and energy. IEEE, pp 104-109

6. Akar F, Tavlasoglu Y, Ugur E, Vural B, Aksoy I (2016) A bidirectional nonisolated multi-input DC-DC converter for hybrid energy storage systems in electric vehicles. IEEE Trans Veh Technol 65(10):7944-7955

7. Amin MM, Mohammed OA (2012) A novel grid-connected multiinput boost converter for HEVs: design and implementation. In: Electric vehicle conference (IEVC), 2012 IEEE international. IEEE, pp 1-7

8. Amirabadi M, Toliyat HA, Alexander WC (2013) A multiport AC link PV inverter with reduced size and weight for stand-alone application. IEEE Trans Ind Appl 49(5):2217-2228

9. Asa E, Colak K, Bojarski M, Czarkowski D (2015) Asymmetrical duty-cycle and phase-shift control of a novel multiport CLL resonant converter. IEEE J Emerg Sel Top Power Electron 3(4):1122-1131

10. Chen Y-M, Yuan-Chuan L (2001) Development of multi-port converters for hybrid wind-photovoltaic power system. In: TENCON 2001. Proceedings of IEEE region 10 international conference on electrical and electronic technology. IEEE, pp 804-808

11. Cornea O, Muntean N, Teodorescu R, Gavris ML (2012) Dual input hybrid buck LC converter for a mixed wind and PV array generation system. In: Power electronics and motion control conference (EPE/PEMC), 2012 15th international. IEEE, pp DS1b. 22-21-DS21b. 22-26

12. Dehghan SM, Mohamadian M, Yazdian A (2010) Hybrid electric vehicle based on bidirectional Z-source nine-switch inverter. IEEE Trans Veh Technol 59(6):2641-2653

\section{SN Applied Sciences}


13. Dehghan SM, Mohamadian M, Yazdian A, Ashrafzadeh F (2010) A dual-input-dual-output Z-source inverter. IEEE Trans Power Electron 25(2):360-368

14. Hajizadeh A, Golkar MA, Feliachi A (2010) Voltage control and active power management of hybrid fuel-cell/energy-storage power conversion system under unbalanced voltage sag conditions. IEEE Trans Energy Convers 25(4):1195-1208

15. Hintz A, Prasanna UR, Rajashekara K (2014) Novel modular multiple-input bidirectional dc-dc power converter (MIPC). In: Power electronics conference (IPEC-Hiroshima 2014-ECCE-ASIA), 2014 international. IEEE, pp 2343-2350

16. Hu S, Liang Z, Fan D, He X (2016) Hybrid ultracapacitor-battery energy storage system based on quasi-Z-source topology and enhanced frequency dividing coordinated control for EV. IEEE Trans Power Electron 31(11):7598-7610

17. Khajesalehi J, Sheshyekani K, Hamzeh M, Afjei E (2015) Highperformance hybrid photovoltaic-battery system based on quasi-z-source inverter: application in microgrids. IET Gener Transm Distrib 9(10):895-902

18. Kim S-K, Kim E-S, Ahn J-B (2006) Modeling and control of a gridconnected wind/PV hybrid generation system. In:Transmission and distribution conference and exhibition, 2005/2006 IEEE PES. IEEE, pp 1202-1207

19. Li D, Gao F, Loh PC, Zhu M, Blaabjerg F (2011) Hybrid-source impedance networks: layouts and generalized cascading concepts. IEEE Trans Power Electron 26(7):2028-2040

20. Peng FZ (2003) Z-source inverter. IEEE Trans Ind Appl 39(2):504-510

21. Pan L (2014) LZ-source inverter. IEEE Trans Power Electron 29(12):6534-6543

22. Siwakoti YP, Loh PC, Blaabjerg F, Town G (2014) Y-source impedance network. In: Applied power electronics conference and exposition (APEC), 2014 twenty-ninth annual IEEE. IEEE, pp 3362-3366

23. Soon JJ, Low K-S (2015) Sigma-Z-source inverters. IET Power Electron 8(5):715-723

24. Nguyen M-K, Lim Y-C, Kim Y-G (2013) TZ-source inverters. IEEE Trans Ind Electron 60(12):5686-5695

25. Qian W, Peng FZ, Cha H (2011) Trans-Z-source inverters. IEEE Trans Power Electron 26(12):3453-3463

26. Adamowicz M, Strzelecka N (2009) T-source inverter. Electr Rev 85(10):1-6

27. Deng K, Mei F, Mei J, Zheng J, Fu G (2014) An extended switched-inductor quasi-Z-source inverter. J Electr Eng Technol 9(2):541-549
28. Nguyen M-K, Lim Y-C, Choi J-H (2012) Two switched-inductor quasi-Z-source inverters. IET Power Electron 5(7):1017-1025

29. Ahmed F, Cha H, Kim S-H, Kim H-G (2014) A high voltage gain switched-coupled-inductor quasi-Z-source inverter. In: Power electronics conference (IPEC-Hiroshima 2014-ECCE-ASIA), 2014 international. IEEE, pp 480-484

30. Deng K, Zheng J, Mei J (2014) Novel switched-inductor quasi-Zsource inverter. J Power Electron 14(1):11-21

31. Zhu M, Yu K, Luo FL (2010) Switched inductor Z-source inverter. IEEE Trans Power Electron 25(8):2150-2158

32. Anderson J, Peng FZ (2008) Four quasi-Z-source inverters. In: Power electronics specialists conference, 2008. PESC 2008. IEEE, pp 2743-2749

33. Anderson J, Peng FZ (2008) A class of quasi-Z-source inverters. In: Industry applications society annual meeting, 2008. IAS'08. IEEE, pp 1-7

34. Liu B, Wang L, Song D, Su M, Yang J, He D, Chen Z, Song S (2018) Input current ripple and grid current harmonics restraint approach for single-phase inverter under battery input condition in residential photovoltaic/battery systems. IEEE Trans Sustain Energy 9(4):1957-1968

35. Singh SA, Carli G, Azeez NA, Williamson SS (2017) Modeling, design, control, and implementation of a modified Z-source integrated PV/grid/EV DC charger/inverter. IEEE Trans Ind Electron 65(6):5213-5220

36. Mathew M, Sathiyan SP (2017) Integrated single stage standalone solar PV inverter. In: 2017 Innovations in power and advanced computing technologies (i-PACT). IEEE, pp 1-6

37. Khan AA, Cha H, Lai J-SJ (2017) Cascaded dual-buck inverter with reduced number of inductors. IEEE Trans Power Electron 33(4):2847-2856

38. Yang F, Ge H, Yang J, Wu H (2018) Dual-Input grid-connected photovoltaic inverter with two integrated DC-DC converters and reduced conversion stages. IEEE Trans Energy Convers 34(1):292-301

39. Ge B, Liu Y, Abu-Rub H, Peng FZ (2017) State-of-charge balancing control for a battery-energy-stored quasi-Z-source cascaded-multilevel-inverter-based photovoltaic power system. IEEE Trans Ind Electron 65(3):2268-2279

Publisher's Note Springer Nature remains neutral with regard to jurisdictional claims in published maps and institutional affiliations. 